\title{
New dental graduates Satisfaction regarding acquired competencies during BDS course
}

\author{
Golam Rabbi ${ }^{1}$, Mohammad Faruque ${ }^{2}$, Humayun Kabir Talukder ${ }^{3}$, Abdal Mia $^{4}$, Tawhidur Rahman ${ }^{5}$,Wakil Ahmed ${ }^{6}$, \\ S M Idris Ali, Rawshan Ara Khanam ${ }^{8}$, Rownak Ara Chowdhury ${ }^{9}$
}

\section{Abstract \\ Objectives}

To assess the level of job satisfaction during BDS course among the new dental graduates according to their views including existing barriers and ways of further improvement.

\section{Materials and methods}

This was a cross sectional type of descriptive study and was carried out for one year. In depth interview were performed using interview schedule among twenty new dental graduates those were very interested and willing to participate in this study.

\section{Results}

Among them 96 new graduates were passed from non-government and 55 in government dental colleges. Of them 53.3\% were female and $46.7 \%$ were male. Satisfaction level on acquired competencies was not in desired level in Oral and maxillofacial surgery, orthodontics and some competencies in prosthodontics. Corresponding teacher, senior doctor and medical officer also by available patient and instrument and materials, good academic environment and good relation with teacher, causes much satisfaction. Main causes of dissatisfaction includes Less availability of the patients and instruments, lack of supervision and feedback in the clinical ward, insufficient practical classes and lack of competent instructors in all level.

\section{Conclusion}

New qualified dentists were more or less satisfied on their acquired competencies in most of the clinical areas. This may be due to having sufficient clinical exposure, experience and teaching time during their undergraduate course. There are several causes of satisfaction and so many causes of dissatisfaction. Co-operative and helpful teachers and senior doctors were very important issue for causing satisfaction. More teacher supervision and more patients for practice is recommended by them.

\section{Key Words:}

\section{Introduction}

Satisfaction is a well researched topic in both academic and non-academic settings. In academic settings, students' satisfaction data helps colleges and universities to make their curriculum more responsive to the needs of a changing $^{1,2}$. It is well known that the most important product of educational institutions is qualified graduates. Students must understand the value of their education and be satisfied

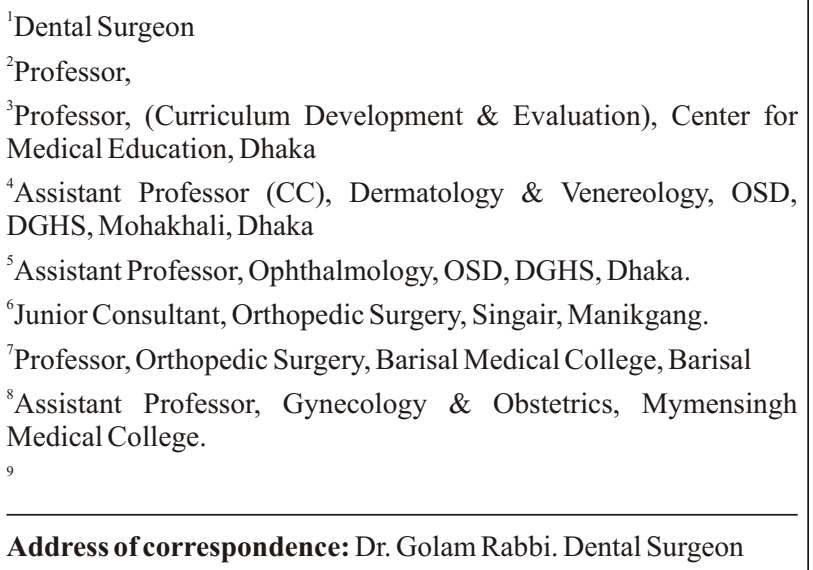

Address of correspondence: Dr. Golam Rabbi. Dental Surgeon

with their overall experience ${ }^{3,4}$. Thus, satisfied students (with the curriculum) are likely to exert more effort in their educational studies by taking actions such as regularly attending their classes and becoming more involved in their coursework and institution. This suggests that while students' satisfaction plays a particularly important role in improving student learning outcomes, it should not be perceived as the only factor that affects student's performance ${ }^{5}$. This is often achieved by the acquisition of knowledge, development of cognitive skills, interpersonal and clinical skills. Also described the development of personal qualities as an important part of achieving competencies ${ }^{6}$. This study was planned to search the answer of the research question- What are the levels of satisfaction of newly passed dental graduates with their acquired competencies from their BDS course? With the objective to assess the level of satisfaction of the newly passed dental graduates of their acquired competencies from their BDS course the study was carried out.

\section{Methodology}

This was a cross sectional type of descriptive study and was carried out for one year in newly passed dental graduates of seven(07) dental outdoors of DentalCollege / unit and one

Bangladesh Journal of Medical Education 2011;2(2):26-31. C 2011 Rabbi et al., publisher and licensee Association of Medical Education. This is an Open Access article which permits unrestricted non-commercial use, provided the original work is properly cited. 
(01) medical university in Dhaka city. In depth interview were performed among 20 new dental graduates those were very interested and willing to participate in this study. Sampling technique was convenience sampling. Data collection instrument was interview schedule. Data was presented by detailed description and percentage.

\section{Ethical Issues}

There was no ethical problem because all the information has been collected anonymously with prior permission of the authority and all the participants has given their opinion voluntarily. Researcher maintained confidentiality in all cases.

\section{Results}

Results of this study were described in two sections. First section deals with the quantitative analysis of level satisfaction on 55 selected competencies gathered from 150 new dental graduates by the self-administered structured questionnaires. The second section describe qualitatively the results of the in-depth interview of 20 respondents. The qualitative portions again describe competencies to which they were satisfied or dissatisfied, the positive and negative factors influencing their satisfaction and areas of further improvements of those competencies.

The mean values of the individual items cutoff point were 3 so on the scores as $<2=$ highly dissatisfactory, $2-3=$ dissatisfactory, $>3-4=$ satisfactory, and $>4=$ highly satisfactory. Mean score of no item was $<2$.There were 18 items in the category of 2- 3 score. The lowest score was 2.35 which were related with oral and maxillofacial surgery and highest score was 4.23 which were related with periodontology and oral pathology. There were 28 items fall into $>3-4$ category. This category was indicating satisfaction of the new graduates. The last group was $>4$ which indicates highly satisfaction. In this category only 5 items were included. The score were 4.07 to 4.23 in relation with paediatric dentistry, conservative dentistry and endodontics, prosthodontics, periodontology and oral pathology.

Most of the new graduates were satisfied in dental pharmacology and paediatric dentistry also satisfied in Periodontology and Oral pathology Conservative dentistry and Endodontics and also in Dental public health. But on Oral and Maxillofacial Surgery and Orthodontics they were not satisfied

\section{Discussion}

In the discussion chapter it was considered that the graduate doctors have optimum competencies in those areas where they were satisfied or highly satisfied. Similarly it was considered that the graduate doctors have inadequate competencies in those areas where they were dissatisfied or highly dissatisfied. Those who were undecided they were excluded from these categories of having sufficient competencies and inadequate competencies.

\section{Dental pharmacology}

In Dental pharmacologyspecial emphasis was given to drugs used in dentistry for the treatment of dental diseases. It was found that majority of the graduates obtained sufficient competency in prescribing appropriate antibiotics for treatment and prevention of infections (77.8\%). Proper knowledge regarding sterilization and disinfection is $(64.4 \%)$ and in using local anesthesia $(85.9 \%)$ of the doctors achieved sufficient competency. Another study done by Boynes SG (2011) ${ }^{7}$ found that educational preparedness and perceive knowledge on local anesthesia related topics (local anesthesia administration, local anesthetic pharmacology and local anesthetic complications) is relatively higher, the results of this study were very similar with the results of the present study. Another study by Firmstone V. R, $(2004)^{8}$ found regarding sterilization \& cross infection, experience was at baseline.

\section{Dental public health}

In the present study it was found that majority of the newly passed graduates were satisfied with their acquired competencies in giving oral hygiene instructions $(82.7 \%)$ which can control and prevent dental disease. But in the community and preventive program, which can reduce the incidence of oral disease in the community, only ( $40.3 \%$ ) of newly passed graduates were satisfied with their acquired competency. Moreover, on promoting oral and systemic disease prevention, $(43.6 \%)$ were not satisfied with their acquired competency. Majority of the graduates, who were satisfied with their competencies in giving oral hygiene instructions, easily acquired the competencies from their own hospital. On the other hand they need to go other places and areas from their hospital for achieving the competencies in community and preventive programs. There were less community based programs rather than hospital based programs although our BDS dental curriculum is focused on competency based and community based (BDS Curriculum, 2007) $)^{9}$. These may be a probable explanation why the majority of newly passed graduates were not satisfied with their acquired competencies in community and preventing programme.

Another study done by Eduardo Bernabé (2006) ${ }^{10}$ showed that dental graduates of the Faculty of Stomatology at the Universidad Peruana Cayetano Heredia perceived themselves more competent in performing some dental public health functions than others. Promotion of general and oral health through health education was the function with the highest self-perceived score. The elaboration of the socioeconomic-cultural diagnosis as well as the oral health diagnosis of the community, the implementation of preventive interventions, and the incorporation of dental practice into personal and community development were the functions with the second highest self-perceived score. The higher scores since the dental public health learning experiences put a higher emphasis on these activities at the undergraduate level. A study conducted by Widstrom E, Martinsson T, and Nilsson B (1988) ${ }^{11}$ for Swedish and Finis graduate it was found that, respondents felt most competent in preventive dentistry. 


\section{Periodontology and Oral pathology}

Periodontology is that branch of dentistry which concern with the diagnosis and treatment of diseases of the supporting structures of the teeth. In the present study it was found that majority of the graduates have acquired sufficient competencies on idea about the condition of the periodontium from their institutes regarding measurement of periodontal pocket $(67.8 \%)$ and measurement of tooth mobility and furcation involvement of tooth $(77 \%)$, diagnosis of plaque $(94.6 \%)$,etc. Moreover, they have acquired competencies in non-surgical procedure for periodontal treatment $(60 \%)$ that they need in their daily practice. Whereas, (38.1\%) of the respondents were satisfied with the acquired competencies in management of common oral anomalies.

A study conducted by Darby IB et al. (2005) ${ }^{12}$ confirms that most graduates were confident to diagnose and treat gingivitis and initial periodontal disease. Another study done by Logan R, Baron J, and Swann c (2009) ${ }^{13}$ for evaluation of an oral pathology, found that they were very much positive in diagnosis, management and treatment planning in oral pathology. Relatively high confidence expressed in periodontal disease which was also reported by Wanigasooriya $\mathrm{N}(2004)^{14}$. The results of these studies are very similar with the results of the present studies.

\section{Prosthodontics}

It is the branch of dentistrydealing with construction of artificial appliances designed to restore and maintain oral function by replacing missing teeth with removable or fixed prosthesis. One of the important steps for making prosthesis is taking impression of dentulous or edentulous jaw. The most commonly used impression material for dentulous jaw is alginate whereas impression compound is for edentulous jaw. In the present study it was seen that the newly passed dental graduates were satisfied with their acquired competencies in taking impression of dentulous jaw with alginate (94.7\%) and making partial denture prosthesis $(75.7 \%)$. On the other hand they were not satisfied with their acquired competencies in taking impression of an edentulous jaw $(29.5 \%)$ and also making removable complete denture prosthesis $(28.6 \%)$ for complete missing teeth restoration. Unavailability of patient, complicated impression technique, difficult manipulation of impression material and elaborate procedure are the probable explanation of the result. Several factors may contribute to such disparity. These include the ADEA finding that only $18.7 \%$ of graduating dental students felt well prepared in prosthodontics, the small number of accredited prosthodontics faculty, lack of an established mentorship program, lack of an advanced graduate program, misconception of the potential specialty income, and lastly, a strong correlation between the perception of the specialty and enjoyment of challenging/complex dentistry and laboratory work which are some of the fundamental components of the practice of prosthodontics. Another study conducted by Matilda Dhima Some $(2012)^{15}$, found that although $76 \%$ of the respondents enjoyed complicated dentistry, and 59\% liked laboratory work, one-fourth of them were indifferent to the experiences they had with prosthodontics-trained faculty. Additionally, only $9 \%$ of the respondents perceived the details of the specialty of prosthodontics to be very well known.

\section{Conservative dentistry and Endodontics}

In the present study most respondent felt that they were satisfied with their acquired competencies in this subject from their institutes. They have achieved all the competencies in the management of dental caries $(90.7 \%)$, restoration of teeth by direct and indirect materials and methods $(89.2 \%)$, restoring endodontically treated teeth $(86.3 \%)$, management of aesthetic problem with tooth defect $(60.5 \%)$, management of pain of pulpul origin $(92 \%)$, performing uncomplicated non-surgical anterior $(89.3 \%)$ and posterior endodontic therapy (63.7), management of common (66.4\%) and complex endodontic complications (38.5\%) etc. Availability of the patient, personal interest of the graduates and more effort given by the teachers may explain why they have achieved most of the competencies in this subject. However, in the present study, it was seen that not all of the newly graduates were satisfied with their acquired competencies in performing hypersensitivity test $(44.9 \%)$, management of complicated non-surgical $(44.0 \%)$ and surgical endodontic therapy $(20.7 \%)$. Unavailability of the patient and as most of the cases is treated by senior or post graduate doctors, the satisfaction with their acquired competencies were comparatively low in those selective cases.

A study conducted by Widstrom E, Martinsson T, and Nilsson B (1988) ${ }^{11}$ for Swedish and Finis graduate found that the respondents felt most competent in cariology. The results of this study were very similar with the results of the present study. Another study done by Gatley S. (2009 $)^{16}$ stated that the aim of dental schools to produce graduates competent in root canal treatment as well as endodontic treatment so that they will be able to define the qualities that make a student competent.A study was conducted by Gina Arena (2007) ${ }^{17}$ found that they were most confident with amal-gam restorations and anterior endodontics, the results of this study were very similar with the results of the present study. Another study done by Lindemann R A and Jrdrychowski J (2002) ${ }^{18}$ found that the students were more familial in esthetic restoration.

\section{Dental radiology}

Majority of the respondent were satisfied with their acquired competencies in interpreting finding in the intraoral x-ray (73.3\%) and to identify $\mathrm{x}$-ray film position of the tooth like upper and lower jaw and right or left of the $\mathrm{X}$ ray film $(68.6 \%)$.

\section{Oral and Maxillofacial Surgery}

In the present study it was seen that majority of the newly passed dental graduates were satisfied with their acquired competencies in performing the non - surgical extraction of permanent erupted teeth $(72 \%)$ and dealing with post 
extraction complication (56.7\%). They have knowledge regarding the contraindications of extraction $(79.7 \%)$, routes of administration of local anesthesia $(75.3 \%)$ and effect of systemic diseases on the oral cavity like diabetes mellitus (79.3\%). However, few of them were satisfied with their acquired competencies in performing surgical extraction of permanent erupted teeth $(45.5 \%)$ and impacted teeth (29.5\%), management of dental emergencies that may occur during dental treatment (37.4\%), diagnosis (36\%) and management (17.3\%) of TMJ dysfunctions management, regarding management of intraoral hard and soft tissue lesion of traumatic (30\%), non -traumatic origin (28.1\%), management of intraoral soft tissue lesions of traumatic origin $(20.8 \%)$, performing haemostatic agent application (31.5\%), diagnosis $(14.1 \%)$ and treatment $(10 \%)$ of trigeminal neuralgia and management of facial paralysis $(6.7 \%)$ etc. Very few of the newly passed graduates achieved competencies regarding management of the Salivary gland diseases $14(9.4 \%)$ Unavailability of the patient is the probable explanation why they were not satisfied with their acquired competencies in those cases. But may be another important probable cause was teacher and logistic support also. A study conducted by Widstrom E, Martinsson T, and Nilsson B (1988) ${ }^{11}$ for Swedish and Finis graduate found that the respondents felt less competent and they felt weakest in oral surgery . According to Patel $\mathrm{J}$ and Fox K (2006) $)^{19}$, surgical extraction of teeth is one of the areas that dental practitioners feel least prepared for by their undergraduate training. Another study conducted by Lindemann R A and Jrdrychowski J (2002) ${ }^{18}$ found that neither group showed improvement on third molar extraction skills which is also similar with the results of the present study. Honey J, Lynch CD, Burke FM and Gilmour ASM $(2011)^{20}$ done a study in Oral surgery in Cork University , they found that the confidence level was very little in dental emergencies.A very similar result was found in the present study.

\section{Orthodontics}

In the present study, it was seen that more than $50 \%$ newly passed dental graduates were not satisfied with their acquired competencies in uncomplicated space analysis and maintenances, management of simple $48(33.3 \%)$ and complex malocclusion 55(36.9\%) which is necessary to achieve proper mastication, normal occlusion as well as aesthetic by using a range of removable appliance. Lack of knowledge about how a treatment plan should carried out, lack of resources, scarcity of faculty, difficulty in obtaining ideal limited treatment patients and less effort given by the teachers may explain why they are not fully satisfied with their acquired competencies in this subject from their institute. However, their skill is limited on making some appliances like Adams, labial bow, spring former, palatal finger spring, self-supporting buccal spring and posterior bite plate etc. A similar study conducted by Widstrom E, Martinsson T, and Nilsson B (1988) ${ }^{11}$ for Swedish and Finis graduate, found that the respondents felt less competent and were weakest in orthodontics, which is very similar with the results of the present study This has resulted in dental graduates entering practice without a strong appreciation of the art and science of orthodontics.

\section{Paediatric dentistry}

Paediatric dentistry is one of the difficult and critical part for a graduate specially in undergraduate level because of communication skill with patient, in depth knowledge in morphology and anatomy of a teeth, eruption time of a teeth which is interrelated with the competencies they want to achieve. In the present study the respondents were satisfied in every competencies like restoration of tooth in primary and mixed dentition $126(84.6 \%)$, conserving tooth structure and preserve pulp vitality to restore form and function by pulp capping 85(56.6\%), performing paediatric pulpul therapy by pulpotomy and pulpectomy $113(75.8 \%)$. All of the above mentioned procedures are essential to maintain the masticatory function, space and aesthetic, prevents pain and also increases self-esteem of a child. They were also satisfied with their competencies in performing nonsurgical extraction of primary teeth $123(82 \%)$ which are required to manage the space for the eruption of permanent teeth. Relatively high confidence expressed in paedodontics which was also reported by Wanigasooriya $\mathrm{N}(2004)^{14}$.

\section{Discussion on In depth interview (Qualitative part)}

This qualitative analysis or in-depth interview was done for when there were probe deeply about unknown aspect of a problem. The respondents are given their own opinion in their own word, there were not give any restriction or they are not rigid about the questionnaire. Where were ask the question to the respondents whom are very cooperative with me or interested with it. In this holistic part of research they also give their personal view to improve the procedure to achieve the competency properly.

Aimed of in depth interview was to explore the factors which influence them to achieve and also constraints which was not influence them about the perceived level of satisfaction from their competencies, causes and how to improve the existing situation.

Majority of the respondents feel more competent on operative dentistry and endodontics for the reason that their teacher, senior and also medical officer help them to achieved it.

On the other hand respondent partially competent are in removal complete denture prosthesis but respondent felt they have not achieved their competency in fixed and removal orthodontics and also in oral and maxillofacial surgery. Some constraints was not influence them to achieve those competencies like less instruments, less patients, teachers are not always presents in the clinical ward to help them, insufficient practical classes and also less competent teacher.

The respondents also gave their opinion how to solve this problem and further improvement of the procedure to achieve the competencies for future new graduate. 
The opinion was more co-operative teacher, more patients to practice on, availability sterilized instruments and materials in the clinical ward, more number of medical officers in the OPD, increased logistic support and merging with modern dentistry. Practical classes were one of the important factor for achieving competency, no political attachments of students or students politics, development or improvements of OPD and prosthetic lab, maintain of logbook properly, more community based programme and also good educational environment on required to achieved those competencies.

After qualitative and quantitive analysis there were some similarities in some of the subject with fewer competencies. In Oral and Maxillofacial surgery and Orthodontics the respondent the respondent felt less satisfied from their competencies. And the rest of the subjects with competencies the graduates felt satisfied with their achieved level.

\section{Limitations of the study}

This study was conducted only in the dental and dental units of medical colleges and university of Dhaka city due to financial constraints, so the result do not represent the opinion of all dental graduates of Bangladesh.

The study population was selected conveniently which also reduce the representativeness of the findings. If they were selected randomly it would be big job to establish communication with all the selected graduates and there were chance that all of them might not agree to participate in the study.

Some of the respondents were busy with their professional work. They did not give enough time to response in the questionnaires.

During in depth interview most of the doctors were unwilling to spent sufficient time. These might introduce inaccurate data.

Due to the unfamiliarity of these educational issues in some cases doctors might response inaccurately.

\section{Conclusion}

From this study the respondents reported that they have acquired greater practical experiences in few disciplines during working with patients in their course. The majority of graduates were satisfied on their acquired competencies in basic subjects but the level of satisfaction was relatively low in clinical subjects in their BDS course. This was due to the help acquired from the corresponding teachers, senior doctors and medical officers and also by available patient, instrument and materials. Furthermore, the respondents desired to acquire more skills in orthodontics, oral surgery and prosthodontics. According to their opinion, less availability of the patients and instruments, lack of supervision and feedback in the clinical ward, insufficient practical classes and lack of competent instructors in all level are the responsible factors and moreover they need a structured and systematic intern period, so that the graduates were not satisfied at desired level in many of the desired competencies.

\section{References}

1. Eyck R, Tews M., and Ballester JM, (2009), Improved Medical Student Satisfaction and Test Performance With a Simulation-Based Emergency Medicine Curriculum: A Randomized Controlled Trial, Paper presented at the ACEP 2008 Research Forum, October 2008, Chicago, IL.

2. Witowski L, (2008), The relationship between instructional delivery methods and students learning preferences: What contributes to students' satisfaction in an online learning environment?, Ph.D desertation, retrieve on February 11, 2012 from, http:// gradworks.umi.com/3310726.pdf

3. Bryant JL, (2006), Assessing expectations and perceptions of the campus experience: The Noel-Levitz Student Satisfaction Inventory, New Directions for Community Colleges, 134. San Francisco: JosseyBass.

4. Özgüngör S, (2010), Identifying Dimensions of students' ratings that best predict students' self efficacy, course value and satisfaction, Eurasian Journal of Educational Research,vol.38,pp. 146-163.

5. Tessema M, Ready K, and Embaye A, (2011), The Effects of Employee Recognition, Pay, and Benefits on Job Satisfaction: Cross Country Evidence. Paper presented at MBAA conference, Chicago, March, 23$25,2011$.

6. Manakil J, George R,(2011),Reviewing Competency in Dental Education, International Journal of dental clinics, vol.3, no.2, pp.33-39.

7. Boynes SG, Zovko J, Bastin MR, Grillo MA, Shingledecker BD,(2011), Dental hygienists' evaluation of local anesthesia education and administration in the United States, Journal Dental Hygiene, Winter, vol.85, no.1, pp.67-74.

8. Firmstone VR, Bullock AD, Bedward J, Frame JW, Hall J(2004), Key skills for newly qualified dentists: an evaluation of a West Midlandsinitiative, British Dental Journal, Supplementary, pp.25-32.

9. BMD\&C Dental curriculum 2007.

10. Bernabé E, Biostat C, Ludeña M A, Beltrán-Neira R J, (2006),Self-Perceived Public Health Competency Among Recent Dental Graduates, Journal of Dental Education, vol.70, no.5.

11. Widstrom E, Martinsson T, Nilsson, (1988), Swedish and Finnish dental practitioners 'opinions of their undergraduate education, Community Dent Oral Epidemiol, vol.16,pp.139-42. 
12. Darby IB, AngkasaF, Duong C, HoD, Legudi S, Pham K, Welsh A, (2005), Factors influencing the diagnosis and treatment of periodontal disease by dental practitioners in Victoria, Australian Dental Journal, vol.50,no.1, pp.37-41.

13. Logan R, Baron J, and Swann C, (2009), Oral pathology in blended space: A pilot study. In Same places, different spaces. Proceedings ascilite. Auckland 2009. http://www.ascilite.org.au/conferences/auckland09/ procs/logan-poster.pdf.

14. Wannigasooriya N,(2004),Students self-assessment of essential skills in dental surgery, British Dental Journal, Supplementary, pp.11-14.

15. Dhima $M$, Vicki $C$, Salinas $T$ J \& Wright $R$ F,(2012),Predoctoral Dental Students' Perceptions and Experiences with Prosthodontics, Journal of Prosthodontics, vol.00,pp.1-9.

16. Gatley, S, Hayes J. and Davies C,(2009), Requirements, in terms of root canal treatment, of undergraduates in the European Union: an audit of teaching practice, British Dental Journal, vol. 207, no. 4, pp. $165-170$.
17. Arena G,Kruger E,Holley D,Millar S, Tennant M,(2007),Western Australian Dental Graduates' Perception of Preparedness to Practice: A Five-Year Follow-Up,Journal of Dental Education, vol.71, no.9.

18. Lindemann RA and Jedrychowski J, (2002),Selfassessed clinical competence: a comparison between students in an advanced dental education elective and in the general clinic, European Journal of Dental Education, vol. 6, pp.16-21.

19. Patel J, Fox K, Grieveson B, Youngson C,(2006), Undergraduate training as preparation for vocational training in England: a survey of vocational dental practitioners' and their trainers' views, British Dental Journal, Supplementary, pp. 9-15.

20. Honey J, Lynch CD, Burke FM and Gilmour ASM,(2011), Ready for practice? A study of confidence levels of final year dental students at Cardiff University and University College Cork, European Journal of Dental Education, vol.15,pp. 98-103. 